Materials and methods Neutralisation of human TNF was assessed in the L929 bioassay. The activity of anti-TNFs at inhibiting lipopolysaccharides (LPS)-driven interleukin $1 \beta$ (IL-1 $\beta$ ) secretion by monocytes was measured by ELISA. To determine apoptosis induction, activated peripheral blood lymphocytes and monocytes were examined by annexin $\mathrm{V}$ staining using flow cytometry. The effect on neutrophil necrosis was measured by myeloperoxidase release. An isotype-matched control was used in all assays except the L929 bioassay.

Results The inhibitory concentration $\left(\mathrm{IC}_{90}\right)$ neutralisation activity in the $\mathrm{L} 929$ bioassay was $0.3 \mathrm{ng} / \mathrm{ml}$ for ETA, $4 \mathrm{ng} / \mathrm{ml}$ for GLM, $15 \mathrm{ng} / \mathrm{ml}$ for ADA and $20 \mathrm{ng} / \mathrm{ml}$ for IFX, versus $2.5 \mathrm{ng} /$ $\mathrm{ml}$ for CZP. CZP was the most potent inhibitor of LPS-driven IL-1 $\beta$ secretion ( $\left.\mathrm{IC}_{50} \sim 0.1 \mathrm{ng} / \mathrm{ml}\right)$, followed by GLM $(20 \mathrm{ng} / \mathrm{ml})$. GLM, ADA, IFX and ETA induced apoptosis of monocytes and lymphocytes to a similar degree. CZP caused no increase in apoptosis above isotype-matched control levels. In the neutrophil necrosis assay, ADA, IFX and GLM caused $70 \%$ necrosis at $100 \mu \mathrm{g} / \mathrm{ml}$, and ETA $48 \%$. CZP did not increase the level of necrosis above the level of the control.

Conclusion The ability of GLM, IFX and ADA to neutralise human TNF was inferior to CZP and ETA. CZP had a different profile to the other anti-TNFs; it was the most potent at inhibiting monocyte LPS-driven IL-1 $\beta$ production, did not induce apoptosis of activated monocytes and lymphocytes and did not cause neutrophil necrosis. The clinical relevance of these in vitro effects is unknown. Nevertheless, these assays show interesting differences between anti-TNFs.

\section{A166 CERTOLIZUMAB PEGOL HAS A DIFFERENT PROFILE FROM OTHER ANTI-TNFS, INCLUDING GOLIMUMAB, IN A VARIETY OF IN VITRO ASSAYS}

G Fossati, ${ }^{1}$ A Nesbitt1 ${ }^{1}$ New Medicines, UCB, Slough, UK

\subsection{6/ard.2010.149013.9}

Background and objectives Differences in structure and in vitro properties of anti-tumour necrosis factor (TNF) agents may account for different modes of action and clinical outcomes. The activities of certolizumab pegol (CZP), etanercept (ETA), infliximab (IFX) and adalimumab (ADA) have been compared using in vitro assays. However, golimumab (GLM) has not previously been evaluated. The objective of this study was to compare the activity of CZP with other anti-TNFs, including GLM, in a range of in vitro assays. 